\title{
ИРЛАНДИЯ В ОРБИТЕ АМЕРИКАНСКИХ ИНТЕРЕСОВ НА ФОНЕ БРЕКЗИТА
}

Аннотация. Британский премьер-министр Т. Мэй 7 июня 2019 г. ушла в отставку с поста лидера Консервативной партии. Она так и не сумела убедить членов Палаты общин утвердить соглашение о брекзите и параллельно вызвала раскол среди однопартийцев. Надежды на «упорядоченный» выход Великобритании из состава Европейского союза (ЕС) остаётся всё меньше, проблема североирландской граниџы до сих пор не решена. На фоне этой неопределённости ирландское правительство защчщщает принцииь Белфастского соглашения 1998 г., которые лежат в основе мирного прочесса на острове. Государственный визит президента США Д. Трампа в Республику Ирландия может стать новым этапом в урегулировании последствий брекзита.

Ключевые слова: Великобритания, Республика Ирландия, США, брекзит, Фине Гэл, Фианна Файл.

После референдума о выходе Великобритании из состава Европейского союза в 2016 г. прошло почти три года, но в ситуации с брекзитом всё ещё не поставлена точка. После сложных и продолжительных переговоров между Лондоном и Брюсселем в ноябре 2018 г. было разработано соглашение о брекзите, которое устроило обе стороны, но вызвало протест большинства депутатов Палаты общин. Главный пункт, который вызвал разногласия, касался режима североирландской границы. Представители ЕС предложили установить режим «бэкстопа», который предполагал членство Великобритании в Таможенном союзе до конца переходного периода (декабрь 2020 г.), чтобы предотвратить установление «жёсткой» границы с Республикой Ирландия ${ }^{1}$. Если стороны так и не сумеют выработать совместное решение по этому вопросу, то Великобритания рискует остаться в Евросоюзе надолго, если не навсегда, на невыгодных для себя условиях. Она не сможет выйти из Таможенного союза в одностороннем порядке и не будет иметь права голоса в руководящих органах $\mathrm{EC}^{2}$.

\section{Отставка Т. Мэй как фактор неопределённости в переговорах по брекзиту}

Большинством голосов в Палате общин депутаты трижды отвергли Соглашение с Европейским союзом, поскольку брекзитёры-тори голосовали против режима «бэкстопа», который ограничивал суверенитет Великобритании, мешал ей проводить независимую торговую политику в будущем. Т. Мэй всё время испытывала давление как со стороны оппозиции в лице лидера лейбористов Дж. Корбина, который не хотел, чтобы Великобритания покидала Таможенный союз, так и со стороны ушедших в отставку членов своего кабинета министров -

(C) Охошин Олег Валерьевич - кандидат исторических наук, старший научный сотрудник Центра британских исследований Отдела страновых исследований Института Европы РАН. Aдрес: 125009, Россия, Москва, ул. Моховая, д. 11, стр. 3. E-mail: ohoshin89@gmail.com.

DOI: http://dx.doi.org/10.15211/vestnikieran3201995100

${ }^{1}$ Agreement on the withdrawal of the United Kingdom of Great Britain and Northern Ireland from the European Union and the European Atomic Energy Community, 25 November 2018. [Online]. URL: https://www.gov.uk/government/ publications/withdrawal-agreement-and-political-declaration.

${ }^{2}$ Ananieva E.V. «Brekzit: v svobodnom padenii», 2019. URL: https://interaffairs.ru/news/show/21907 (дата обращения: 12.06.2019). 
Б. Джонсона и Д. Дэвиса, уверенных, что лучше Великобритании «уйти по-английски», чем оставаться «вассальным государством» внутри ЕС.

Финальным аккордом в противостоянии депутатов и правительства стало заявление премьер-министра 21 мая 2019 г. Осознав, что напрямую давить на Палату общин не удаётся, Т. Мэй пообещала парламентариям провести голосование о повторном референдуме по брекзиту, но только после того как они одобрят проект соглашения о брекзите. На этот раз премьерминистр серьёзно переоценила собственные силы - депутаты-консерваторы призвали председателя парламентского Комитета 1922 Г. Брейди потребовать её добровольной отставки.

Т. Мэй покинула пост лидера Консервативной партии, так и не сумев реализовать свою главную политическую задачу - завершить процедуру брекзита. Её деятельностью на посту главы правительства были недовольны как однопартийцы, так и рядовые британцы. Согласно опросу общественного мнения в марте 2019 г., 50,2\% респондентов указали, что хотят отставки Т. Мэй, а 41,5\% отметили, что парламентарии поступили правильно, когда не поддержали её соглашение с Европейским союзом ${ }^{1}$. На выборах в Европарламент в мае 2019 г., в которых Великобритании пришлось участвовать из-за переноса её выхода из ЕС до 31 октября 2019 г., консерваторы потерпели сокрушительное поражение и потеряли 15 мандатов, оставив за собой только 4, в то время как в лидеры вышли Партия брекзита Н. Фараджа (29 мандатов) и либерал-демократы (16 мандатов) ${ }^{2}$. Таким образом, Великобританию в Европарламенте будут представлять политические силы, которые выступают за противоречащие друг другу сценарии будущих взаимоотношений страны с Евросоюзом. Н. Фарадж считается у себя на родине одним из главных евроскептиков, лидер либерал-демократов В. Кейбл - из лагеря еврооптимистов, а лидер лейбористов Дж. Корбин хочет, чтобы страна осталась в Таможенном союзе, но выступает за его реформирование.

Остаётся неясным, какой в итоге станет правительственная стратегия по вопросу брекзита с избранием нового лидера Консервативной партии, который займёт и пост премьер-министра. Свои кандидатуры предложили одиннадцать членов партии, среди которых в первую очередь можно выделить бывшего главу МИД Великобритании Б. Джонсона. Этот политик зарекомендовал себя одним из самых жёстких «брекзитёров», постоянно обрушиваясь с острой критикой на переговорную стратегию Т. Мэй. Особенно непримиримой его конфронтация с премьер-министром стала после того, как она предложила в июле 2018 г. свой «план Чеккерс», который предполагал сохранение доступа Великобритании на Единый европейский рынок при условии, что она будет подчиняться правилам и стандартам Европейского союза в сфере производства товаров и торговли. В знак протеста Б. Джонсон подал в отставку с поста главы МИД ${ }^{3}$. В случае, если его выберут лидером партии, он постарается как можно скорее завершить брекзит даже без сделки, несмотря на негативные последствия, которые могут произойти в результате такого неконтролируемого выхода страны из ЕС.

\section{Визит Д. Трампа в Республику Ирландия}

На фоне политической неопределённости в Соединённом Королевстве особенно показательным был трёхдневный государственный визит Д. Трампа по приглашению Елизаветы II в начале июня 2019 г. Американский президент - убеждённый сторонник брекзита и нацелен

\footnotetext{
${ }^{1}$ «Half of UK voters want Theresa May to resign: poll». 17.05.2019. URL: https://www.politico.eu/article/poll-half-ofuk-voters-want-theresa-may-to-resign/ (дата обращения: 12.06.2019).

${ }^{2}$ The official site of European Parliament. 2019. Results of the 2019 European Parliament elections in the UK, [Online]. URL: http://www.europarl.europa.eu/unitedkingdom/en/european-elections/european_elections/results2019.html (дата обращения: 12.06.2019).

3 «Boris Johnson's resignation letter and Mav's reply in full», 09.07.2018. URL: https://www.bbc.com/news/ukpolitics-44772804 (дата обращения: 12.06.2019).
}

Научно-аналитический вестник ИЕ РАН, 2019, №3 
на заключение в будущем двустороннего торгового соглашения с Великобританией, которое он уже называет «феноменальным». За этим громким эпитетом на самом деле скрывается стремление открыть доступ американским компаниям во все секторы британской экономики, которая будет ослаблена после брекзита. Д. Трамп обратил своё внимание и на соседнюю Республику Ирландия, всерьёз обеспокоенную решением пограничного вопроса, который остаётся основной повесткой дня в переговорах премьер-министра Л. Варадкара с представителями ЕС.

Д. Трамп впервые после вступления в должность президента США посетил 5 июня 2019 г. Республику Ирландия. Главной целью его визита стало обсуждение с главой местного правительства возможных последствий брекзита. В ходе встречи с премьер-министром Л. Варадкаром он подчеркнул, что администрация США будет поддерживать мирный процесс, который складывался после Белфастского соглашения. В первую очередь, обе стороны волнует вопрос, каким будет статус североирландской границы после брекзита. В настоящее время она остаётся открытой, и граждане Евросоюза могут беспрепятственно её пересекать. По подсчётам экспертов, через границу проезжают до 6 тыс. грузовиков с товарами, а также её переходят до 30 тыс. человек в день ${ }^{1}$.

Правительство Ирландии пока не подготовилось к угрозе «жёсткого» брекзита и не представляет, как в будущем будет закрывать границу и усиливать таможенный контроль. Её протяжённость составляет 500 км, и она часто проходит в весьма причудливых местах - например, условно делит пополам посёлки и даже жилые и коммерческие постройки. Соёдиненному Королевству и Республике Ирландия придётся ежегодно выделять из бюджета огромные средства, чтобы создать необходимую инфраструктуру и содержать увеличенный штат пограничных служб.

Визит Д. Трампа в Республику Ирландия можно рассматривать как определённую дань уважения исторической преемственности - администрация Б. Клинтона активно участвовала в миротворческом процессе и содействовала заключению Белфастского соглашения, а нынешний президент заявляет, что будет контролировать его соблюдение. Тем не менее, не стоит забывать, что США преследует, в первую очередь, экономические интересы. Республика Ирландия представляет особую важность для американских компаний, потому что корпоративный налог для иностранных резидентов там составляет всего $12,5 \%$, в то время как в Штатах его ставка значительно выше - $21 \%^{3}$. Предприниматели из США испытывают дополнительные трудности из-за торговой войны, которую Д. Трамп ведёт с Китаем, поэтому с радостью воспользуются шансом сократить издержки по налогообложению.

Правительство Республики Ирландия заинтересовано привлечь в свою страну долгосрочные американские инвестиции, особенно в связи с негативными экономическими перспективами брекзита. По данным К. Саммона, директора по международным связям Государственного агентства Республики Ирландия по привлечению зарубежных инвестиций, вклад Соединённых Штатов в ирландскую экономику составляет около 70\% от общего объёма иностранных вложений ${ }^{4}$. Ирландский министр финансов П. Донохью заявил, что некоторые кор-

\footnotetext{
${ }^{1}$ «Brexit and the Irish border explained: why the headache is not going away any time soon», 26.02.2019. URL: https:// www.telegraph.co.uk/politics/0/brexit-irish-border-explained-headache-not-going-away-time-soon/ (дата обращения: 12.06.2019).

2 Taxes Consolidation Act, 1997 [Online]. ULR: http://www.irishstatutebook.ie/eli/1997/act/39/enacted/en/pdf (дата обращения: 12.06.2019).

${ }^{3}$ Tax Cuts and Jobs Act, 2017 [Online]. URL: https://www.congress.gov/115/bills/hr1/BILLS-115hr1enr.pdf (дата обращения: 12.06.2019).

${ }_{4}^{4}$ «rump visit highlights crucial US-Irish economic ties», 05.06.2019. URL: https://www.bbc.com/news/world-europe48514478 (дата обращения: 12.06.2019).
}

Научно-аналитический вестник ИЕ РАН, 2019, №3 
порации уже переносят на остров свои штаб-квартиры. Страна привлекательна для американцев тем, что произведённая там продукция не подпадает под повышенные таможенные пошлины, которые ввели в ЕС и Китае на импорт товаров из США. Кроме того, американским компаниям, несмотря на протекционистскую политику Д. Трампа, экономически невыгодно возвращать свои головные офисы на родину, где их содержание обойдётся дороже, поэтому Республика Ирландия может стать для них необходимым «убежищем», пока США и Китай пытаются ослабить друг друга в торговой войне.

Тем не менее, репутация Д. Трампа как последовательного сторонника брекзита может негативно сказаться на международных и экономических связях США и Республики Ирландия. В стране ещё со времён британского референдума 2016 г. о членстве страны в ЕС среди местных политических сил сложился прочный консенсус: все они высказались негативно по поводу брекзита и продолжают отстаивать принципы евроинтеграции. Переговоры Д. Трампа и Л. Варадкара могут подорвать ещё сильнее авторитет правящей партии Фине Гэл среди электората. В 2019 г. личный рейтинг Л. Варадкара среди ирландцев опустился на рекордно низкий уровень за весь срок его премьерства - 36\%, а популярность его партии снизилась к марту на семь пунктов - до $31 \%$. ${ }^{1}$ Этот спад популярности был связан с громким инцидентом в Уотерфорде, когда правительство проигнорировало жалобы персонала местной клиники на недостаток финансирования и устаревшее оборудование.

Объектом острой критики стала также неспособность правящей партии Фине Гэл решить жилищный кризис в Ирландии. В первой половине 2000-х местный строительный сектор развивался быстрыми темпами и даже рассматривался в качестве одного из «локомотивов» национальной экономики. Строительство составляло 25\% ВВП страны к 2008 г., в этой отрасли было занято почти $18 \%$ рабочей силы ${ }^{2}$. Для увеличения объёма кредитования банки предлагали низкие процентные ставки, пользуясь членством в Экономическом и валютном союзе ЕС, которое предоставляло доступ к внешним кредитным рынкам. Мировой финансово-экономический кризис 2008 г. нарушил эту идиллию - «пузырь» в сфере ипотечного кредитования лопнул, спрос на жильё резко упал, а недвижимость стала стремительно дешеветь. Её активно скупали т.н. «фонды-стервятники» (vulture funds), затем значительно подняв цену. В результате у них в собственности оказалась большая часть всей жилой недвижимости в стране.

Особенно остро стоит вопрос жилья в Дублине, где арендная плата в 2019 г. выросла на $6,8 \%$ и в среднем составляет 2000 евро $^{3}$. Коренным дублинцам приходится переезжать в пригород, потому что они больше не могут позволить себе жильё в столице. Вслед за кризисом жилья появляется и проблема бездомности. В Ирландии количество людей, которым негде жить, неуклонно растёт и в настоящее время превышает 10 тыс. человек. Правительство Л. Варадкара оказалось неспособным решить эти проблемы - оно пообещало к 2020 г. увеличить количество социального жилья до 130 тыс. единиц, но бо́льшая часть из них будет предоставляться из частного сектора по схеме Housing Assistance Payment ${ }^{4}$, которая плохо реализована

\footnotetext{
${ }^{1}$ «Leo Varadkar nightmare: approval ratings slump for Irish PM to lowest yet», 11.05.2019. URL: https://www. express.co.uk/news/politics/1125919/ireland-news-leo-varadkar-approval-rating-opinion-polls-fine-gael-fianna-fail?utm source=traffic. outbrain\&utm medium=traffic.outbrain\&utm term=traffic.outbrain\&utm content=traffic. outbrain\&utm campaign=traffic.outbrain (дата обращения: 12.06.2019).

${ }^{\overline{2}}$ Kelly M. The Irish credit bubble. Understanding Ireland's economic crisis: prospects for recovery. Dublin. 2010. 54.

3 «It's now more expensive to rent than pay a mortgage», 13.05.2019. URL: https://www.irishpost.com/news/nowexpensive-rent-pay-mortgage-across-ireland-166711 (дата обрашения: 12.06.2019).

${ }_{4}^{4}$ «Помощь в аренде социального жилья» (англ. Housing Assistance Payment) - форма поддержки долгосрочной аренды социального жилья в Ирландии, предоставляющая семьям льготные условия по выплатам арендной платы.
}

Научно-аналитический вестник ИЕ РАН, 2019, №3 
в густонаселённых районах страны, где местным арендодателям выгоднее сдавать жильё по рыночным ценам. Правительство Л. Варадкара неоднократно становилось объектом нападок со стороны Шинн Фейн. Заместитель лидера Шинн Фейн П. Догерти заявил, что оно состоит «из богатых мальчиков и девочек, которые поставили перед собой неадекватные задачи» 1 .

На волне подобной критики правительство меньшинства Л. Варадкара остаётся достаточно консолидированным. Глава МИД Ирландии С. Ковени заявил, что партии Фине Гэл и Фианна Файл продолжат совместную работу в правительстве, опираясь на Соглашение о доверии и поддержке, которое они заключили между собой в 2016 г. ${ }^{2}$

Несмотря на то, что часть политических экспертов считает вероятными в стране досрочные парламентские выборы, правительство разуверило их в этом. Тем не менее, у двух партий есть разногласия относительно проекта государственного бюджета, который должен быть представлен к октябрю 2019 г. По данным Ирландского фискального консультативного совета, правительство будет располагать в бюджете всего лишь дополнительными 600 млн евро, которые оно может использовать либо для увеличения социальных расходов, либо для снижения налоговой ставки. В то время как Фианна Файл планирует выделить дополнительные средства на социальное обеспечение и развитие здравоохранения, Фине Гэл считает её инициативы излишне дорогостоящими для государственного бюджета.

\section{Выводы}

Неопределённая политическая ситуация в Великобритании, вызванная выборами нового лидера Консервативной партии и предстоящей отставкой Т. Мэй с поста премьер-министра, держит в напряжении ирландское правительство. Л. Варадкар в данной ситуации продолжает отстаивать принципы Белфастского соглашения 1998 г., которое установило прозрачную границу с соседней Северной Ирландией.

В случае «жёсткого» брекзита ирландской экономике будет нанесён серьёзный ущерб и появятся предпосылки для разжигания нового этно-религиозного конфликта. Поэтому премьер-министр будет добиваться привлечения внимания к этой проблеме не только представителей Евросоюза, но и администрации США, которая традиционно способствует миротворческому процессу на острове и заинтересована в расширении торгово-экономического сотрудничества с Республикой Ирландия.

\section{Литература}

Ananieva E.V. «Brekzit: v svobodnom padenii». 2019 [Online]. URL: https://interaffairs.ru/ news/show/21907 (дата обращения: 12.06.2019).

Kelly M. The Irish credit bubble. Understanding Ireland's economic crisis: prospects for recovery. Blackhall Publishing, Dublin, IE. 2010.

\section{References}

Agreement on the withdrawal of the United Kingdom of Great Britain and Northern Ireland from the European Union and the European Atomic Energy Community, 25.11. 2018 [Online]. URL: https://www.gov.uk/government/publications/withdrawal-agreement-and-political-declaration.

\footnotetext{
${ }_{1}$ «Sinn Féin claims Fine Gael out of touch with "cost-of-living crisis"», 16.05.2019. URL: https://www.irishtimes. com/news/politics/oireachtas/sinn-f\%C3\%A9in-claims-fine-gael-out-of-touch-with-cost-of-living-crisis-1.3894753 (дата обращения: 12.06.2019).

2 «Ireland's Brexit unity wobbles as calls for general election grow», 11.06.2019. URL: https://www.express.co.uk/ news/politics/1139237/ireland-brexit-news-general-election-Simon-Coveney-Fianna-Fail-Fine-Gael (дата обращения: 12.06.2019).
} 
«Half of UK voters want Theresa May to resign: poll», 17.05.2019. URL: https://www.politico. eu/article/poll-half-of-uk-voters-want-theresa-may-to-resign/ (дата обращения: 12.06.2019).

The official site of European Parliament, 2019. Results of the 2019 European Parliament elections in the UK [Online]. URL: http://www.europarl.europa.eu/unitedkingdom/en/europeanelections/european_elections/results2019.html (дата обращения:12.06.2019).

«Boris Johnson's resignation letter and May's reply in full», 09.07.2018. URL: https://www.bbc.com/news/uk-politics-44772804 (дата обращения: 12.06.2019).

«Brexit and the Irish border explained: why the headache is not going away any time soon», 26.02.2019. URL: https://www.telegraph.co.uk/politics/0/brexit-irish-border-explained-headachenot-going-away-time-soon/ (дата обращения: 12.06.2019).

Taxes Consolidation Act, 1997 [Online]. URL: http://www.irishstatutebook.ie/eli/1997/act/39/ enacted/en/pdf (дата обращения: 12.06.2019).

Tax Cuts and Jobs Act, 2017 [Online]. URL: https://www.congress.gov/115/bills/hr1/BILLS115hrlenr.pdf (дата обращения: 12.06.2019).

«Trump visit highlights crucial US-Irish economic ties», 05.06.2019. URL: https://www.bbc.com/news/world-europe-48514478 (дата обращения: 12.06.2019).

«Leo Varadkar nightmare: approval ratings slump for Irish PM to lowest yet», 11.05.2019. URL: https://www.express.co.uk/news/politics/1125919/ireland-news-leo-varadkar-approval-ratingopinion-polls-fine-gael-fianna-fail?utm_source=traffic.outbrain\&utm_medium=traffic.outbrain\& utm_term=traffic.outbrain\&utm_content=traffic.outbrain\&utm_campaign=traffic.outbrain （дата обращения: 12.06.2019).

«It's now more expensive to rent than pay a mortgage», 13.05.2019. URL: https://www. irishpost.com/news/now-expensive-rent-pay-mortgage-across-ireland-166711 (дата обращения: 12.06. 2019).

«Sinn Féin claims Fine Gael out of touch with "cost-of-living crisis"», 16.05.2019. URL: https://www.irishtimes.com/news/politics/oireachtas/sinn-f\%C3\%A9in-claims-fine-gael-out-oftouch-with-cost-of-living-crisis-1.3894753 (дата обращения: 12.06.2019).

«Ireland's Brexit unity wobbles as calls for general election grow», 11.06.2019. URL: https://www.express.co.uk/news/politics/1139237/ireland-brexit-news-general-election-SimonCoveney-Fianna-Fail-Fine-Gael (дата обращения: 12.06.2019).

\section{The Republic of Ireland in the Sphere of American Interests on the Background of Brexit}

Author. Oleg Okhoshin, Candidate of Sciences (History), Senior Researcher of the Centre for British Studies, Department of Countries Studies, Institute of Europe, Russian Academy of Sciences. Address: 11-3, Mokhovaya str., Moscow, Russia, 125009; E-mail: ohoshin89@ gmail.com.

Abstract. British Prime Minister T. May on June 7, 2019 has left the post of leader of the Conservative Party. She wasn't able to convince the members of the House of Commons to approve the Withdrawal Agreement, at the same time causing a split among party members. Hopes for an "orderly" Brexit fade and the problem of the Northern Ireland border has not been resolved yet. Under uncertainty the Irish government defends the principles of the Belfast Agreement 1998, which are at the core in the island's peace process. The US President D. Trump's visit to the Republic of Ireland may be a new stage in the settlement of Brexit consequences.

Keywords: Great Britain, Republic of Ireland, the United States, Brexit, Fine Gael, Fianna Fail.

DOI: http://dx.doi.org/10.15211/vestnikieran3201995100 